\title{
Effect of arginine deficiency on arginine-dependent post-translational protein modifications in mice
}

\author{
Karin L. Kwikkers ${ }^{1}$, Jan M. Ruijter ${ }^{1}$, Wil T. Labruyère ${ }^{1}$, Kathryn K. McMahon ${ }^{2}$ and Wouter \\ H. Lamers ${ }^{1} *$ \\ ${ }^{1}$ AMC Liver Center and Department of Anatomy and Embryology, Academic Medical Center, University of Amsterdam, \\ Meibergdreef 69-71, 1105 BK, Amsterdam, The Netherlands \\ ${ }^{2}$ Department of Pharmacology, Texas Tech University Health Sciences Center, Lubbock, USA
}

(Received 28 January 2004 - Revised 18 October 2004 - Accepted 19 October 2004)

\begin{abstract}
Transgenic mice that overexpress arginase-I in their small-intestinal enterocytes suffer from a pronounced, but selective decrease in circulating arginine levels during the suckling period, resulting in impaired growth and development of hair, muscle and immune system. In the present study, we tested the hypothesis that the arginine-deficiency phenotype is caused by arginine-specific post-translational modifications, namely, an increase in the degree of mono-ADP-ribosylation of proteins because of reduced competition by free arginine residues and/or an increase in protein-tyrosine nitration because of an increased $\mathrm{O}_{2}$ - production by NO synthases in the presence of limiting amounts of arginine. Arginine ADP-ribosylation and tyrosine nitration of proteins in the affected organs were assayed by Western blot analysis, using specific anti-ADP-ribosylarginine and protein-nitrotyrosine antisera. The composition of the group of proteins that were preferentially arginine ADP-ribosylated or tyrosine-nitrated in the respective organs was strikingly similar. Arginine-deficient mice differed from their controls in a reduced ADP-ribosylation of a $130 \mathrm{kDa}$ and a $65 \mathrm{kDa}$ protein in skin and an increased protein nitration of an $83 \mathrm{kDa}$ protein in bone marrow and a $250 \mathrm{kDa}$ protein in spleen. Since only $20 \%$ of the visualised proteins were differentially modified in a subset of the affected organs, our findings appear to rule out these prominent arginine-dependent post-translational protein modifications as mediators of the characteristic phenotype of severely arginine-deficient mice.
\end{abstract}

Transgenic mice: Mono-ADP-ribosylation: Tyrosine nitration: Western blot analysis

The metabolic fates of arginine, being a precursor for the synthesis of proteins, NO, agmatine, creatine, polyamines and an intermediate in the detoxification of ammonia (Fig. 1), are manifold. Despite these crucial functions, arginine is a conditional essential amino acid for mammals, meaning that endogenous synthesis provides for only part of its daily requirements and that an increased demand or a decreased dietary supply can cause a deficiency in arginine (Visek, 1984).

It is well known that a dietary source of arginine is required for normal development and growth of most mammals (Visek, 1984), but also that milk barely suffices in this respect (Davis et al. 1993). In agreement with these data, we observed that transgenic mice ('F/A') that overexpress the enzyme arginase-I in their small-intestinal enterocytes from the late fetal period onwards (De Jonge et al. $2002 a$ ) suffer from a pronounced, but selective decrease in circulating arginine levels during the suckling period. This is because the enterocytes of the small intestine are the predominant source of endogenously produced arginine in suckling mammals (Herzfeld \& Raper, 1976; Hurwitz \& Kretchmer, 1986; Nagy \& Kretchmer, 1988; Riby et al.
1990; Wu \& Knabe, 1995; Wu, 1997; De Jonge et al. 1998). The degree of arginine deficiency in such mice corresponds with impairment of growth and development of hair, muscle and immune system (De Jonge et al. 1998, $2002 a, b)$. The phenotype could be rescued by arginine injections, but the mechanism underlying the argininedeficiency phenotype remains unknown. We did establish that this phenotype did not arise from a deficient availability of arginyl-tRNA, creatine or polyamines (De Jonge et al. 2002a). In this study, we tested the hypothesis that the arginine-deficiency phenotype is caused by arginine-specific post-translational modifications, namely, an increase in the degree of mono-ADP-ribosylation of proteins because of a reduced competition by free arginine residues and/or an increase in protein-tyrosine nitration because of an increased $\mathrm{O}_{2}^{-}$production by $\mathrm{NO}$ synthases in the presence of limiting amounts of arginine.

Mono-ADP-ribosyltransferase (EC 2.4.2.31) modifies proteins by attaching the ADP-ribose moiety from $\mathrm{NAD}^{+}$to arginine, diphthamine (modified histidine), serine, threonine or cysteine residues in acceptor proteins (Hsia et al. 1985; Ziegler, 2000). The consequence of 


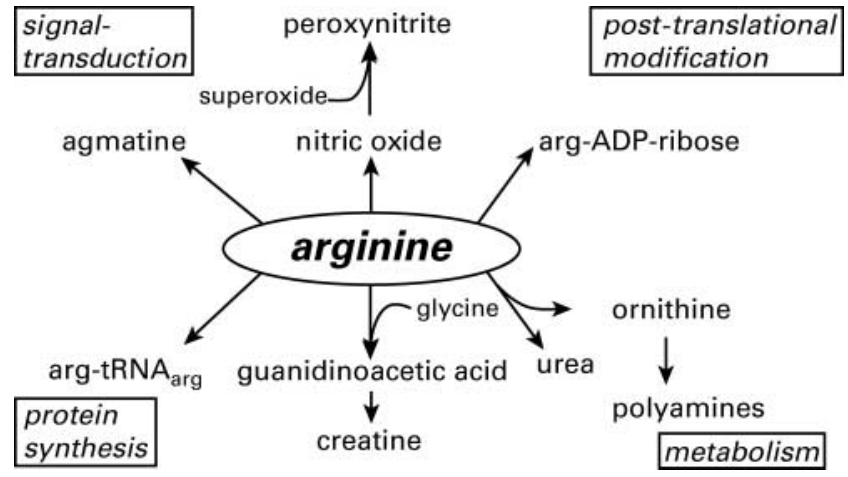

Fig. 1. Schematic representation of the fates of arginine and their involvement in signal transduction, post-transcriptional modification, metabolism and protein synthesis.

mono-ADP-ribosylation of arginine residues is that the ADP-ribosylated protein loses positive charges, so that the physiochemical properties and, hence, the functionality of the protein changes. Five arginine-specific mammalian ADP-ribosyltransferases have been characterised molecularly (Okazaki \& Moss, 1999). Since these ADP-ribosyltransferases are not only able to monoADPribosylate amino acid residues in proteins, but also free amino acids such as arginine (McDonald \& Moss, 1994; Tsuchiya \& Shimoyama, 1994), we hypothesised that arginine deficiency could increase the degree of mono-ADP-ribosylation of proteins because of a reduced competition by free arginine residues.

Under conditions of L-arginine deficiency, neuronal and inducible NO synthases generate, in addition to NO, superoxide ion $\left(\mathrm{O}_{2^{-}}\right)$(Xia et al. 1996; Xia \& Zweier, 1997). Peroxynitrite, the powerful oxidant formed from NO and $\mathrm{O}_{2}^{-}$, is capable of nitrating biomolecules. The nitration of protein-tyrosine residues generates 3-nitrotyrosine. Tyrosine nitration can interfere with signal transduction both by preventing and imitating tyrosine phosphorylation effects (Greenacre \& Ischiropoulos, 2001; Klotz et al. 2002; Minetti et al. 2002). We hypothesised that in our arginine-deficient F/A mice, NO synthase produces sufficient $\mathrm{O}_{2}-$ to allow formation of peroxynitrite and nitration of tyrosine residues in proteins. As for ADP-ribosylation, this second hypothesis predicts that the degree of proteintyrosine nitration is higher in F/A-2 than in wild-type mice.

\section{Material and methods}

\section{Tissues}

F/A-2 transgenic mice were maintained in our local colony as hemizygotes (De Jonge et al. 2002a). Animal care was in accordance with the institutional guidelines of the University of Amsterdam. Tissues from 18-21-d-old homozygous F/A-2 mice and their wild-type littermates were collected and stored at $-80^{\circ} \mathrm{C}$ until analysis. Each bonemarrow sample was collected from a pool of six femurs to obtain sufficient material. Muscle samples were taken from the calf (M. Triceps surae) of the lower leg. Skin samples were taken from the back of the animals after shaving. Tissues were homogenised in 0.25 M-sucrose. Muscle and skin homogenates were additionally sonicated three times for $15 \mathrm{~s}$, with intervals of $45 \mathrm{~s}$, on ice. Protein was determined using the bicinchoninic acid protein assay reagent as prescribed by the manufacturer (Pierce, Rockford, IL, USA).

\section{Western blot analysis}

Aliquots of the homogenates, containing $50 \mu \mathrm{g}$ protein, $70 \mathrm{~mm}$-Tris $\mathrm{pH} 6.8,33 \mathrm{~mm}-\mathrm{NaCl}, 1 \mathrm{~mm}-\mathrm{Na}_{2}$ EDTA, $2 \%$ SDS, $10 \%$ glycerol and, in case of ADP-ribosylation, $5 \% \beta$-mercaptoethanol, were boiled for $3 \mathrm{~min}$ and electrophoresed on $7.5 \%$ SDS-polyacrylamide gels at $150 \mathrm{~V}$. The proteins were transferred to polyvinylidene fluoride (PVDF) membrane (Immobilon-P, Millipore, Billerica, MA, USA) by electrophoresis for $4 \mathrm{~h}$ at $0.2 \mathrm{~A}$ in $25 \mathrm{~mm}-$ ethanolamine/glycine $\mathrm{pH} 9.5 / 20 \%$ methanol to assure a complete transfer. Both for SDS-PAGE and blotting, the Mini-PROTEAN 3 Electrophoresis Cell/Mini Trans-Blot Modules (Bio-Rad Laboratories, Inc., Hercules, CA, USA) were used. Equal loading of the lanes was checked by staining the blots with amido black $(0 \cdot 1 \%$ amido black in $10 \%$ methanol and $10 \%$ acetic acid), followed by destaining the blots with methanol. The integrated optical density of each lane was determined in a digital image of the blot, which was obtained using the top-illumination mode of the Lumi-Imager (Roche, Mannheim, Germany).

\section{ADP-ribosylation}

Bone marrows of three animals were pooled to obtain sufficient tissue and three samples were analysed for both groups. For spleen, three and four samples were analysed in duplicate for wild-type and F/A-2 mice, respectively. For thymus, three samples were analysed for both groups. For muscle, four and five samples were analysed in duplicate for wild-type and F/A-2 mice, respectively. For skin, five and seven samples were analysed for wildtype and F/A-2 mice, respectively. After blocking with Tris-Buffered Saline-Tween (TBST) buffer (50 mM-Tris $\mathrm{pH} 7.5,0.15 \mathrm{M}-\mathrm{NaCl}, 0.1 \%$ Tween-20) and $5 \%$ non-fat milk powder for approximately $5 \mathrm{~h}$, the blots were incubated overnight with rabbit anti-ADP-ribosylarginine antiserum (Schwab et al. 2000) at a dilution of 1:5000 in TBST buffer/1\% non-fat milk powder or, in a single experiment, with rabbit ADP-ribosylguanidinobutyrate affinity-purified anti-ADP-ribose antiserum (Meyer \& Hilz, 1986) at 1:2000 in TBST (a generous gift from Dr H. Hilz). Antibody binding was detected with a goat-anti-rabbit alkaline-phosphatase complex (Sigma-Aldrich Corp, St. Louis, MO, USA; 1:5000 in TBST buffer). Subsequently, the blots were washed in NTM buffer $(100 \mathrm{~mm}-\mathrm{NaCl}$, $100 \mathrm{~mm}$-Tris $\mathrm{pH} 9.5,12.5 \mathrm{~mm}-\mathrm{MgCl}_{2}$ ), followed by incubation with the chemiluminescent substrate CDP-star (Roche, Mannheim, Germany; 1:100 in NTM buffer). Chemiluminesence at $465 \mathrm{~nm}$ was registered for 3 min with the Lumi-Imager. Each blot contained four or five F/A2 and four or five wild-type samples and a broad range $(6-175 \mathrm{kDa})$ prestained protein marker (New England Biolabs, Inc., Beverly, CA, USA). The degree of ADPribosylation of a protein band on a blot (relative ADP-ribosylation) was expressed as the ratio of the light emission of 
the specific protein band in the chemiluminescent image and the optical density of the total protein content of the same lane in the amido black image according to the equation:

\section{Relative ADP-ribosylation}

$=($ Light emission by the specificband-Background $) /$

(Optical density of the total lane-Background)

Local background staining was determined by measuring areas next to the band or lane.

The specificity of the rabbit anti-ADP-ribosylarginine antiserum was tested by treating blots with $1 \mathrm{M}-\mathrm{NH}_{2} \mathrm{OH}$ (pH 7.4) or $5 \mathrm{U} / \mathrm{ml}$ phosphodiesterase-1 (Schwab et al. 2000). These treatments reduced the staining intensity of the major bands to $25-35 \%$ and $30-40 \%$ of controls, respectively, and made the minor bands undetectable.

\section{Tyrosine nitration}

For bone marrow, muscle and skin, four samples were analysed for F/A-2 and control mice. Bone marrows of three animals were pooled to obtain sufficient tissue. For spleen and thymus, five and four samples were analysed in duplicate for F/A-2 and wild-type mice, respectively.
To assess protein-tyrosine nitration levels (relative tyrosine nitration), the same approach as described for ADP-ribosylation was used. The primary antibody was a monoclonal antibody against nitrotyrosine (ter Steege et al. 1998) (a generous gift from Dr W. Buurman) in a dilution of 1:500 in TBST, while the secondary antibody was an alkaline-phosphatase labelled goat-anti-mouse antibody (Sigma-Aldrich Corp., 1:30 000 in TBST buffer) and the chemiluminescent substrate Lumi-Phos (Pierce).

\section{Statistical analysis}

The results did not permit us to assume that the data were normally distributed. For that reason the non-parametric Mann-Whitney test was used for statistical analysis. Interexperimental variation in chemiluminescence in duplicate assays was removed using log-transformed values and the General Linear Model ANOVA without interaction (SPSS version 10.0.7, SPSS Inc., Chicago, IL, USA).

\section{Results}

F/A-1 and F/A-2 mice express transgenic arginase-I in all enterocytes, but F/A-2 mice differ from F/A-1 mice by a 2-fold higher level of expression of transgenic arginase.

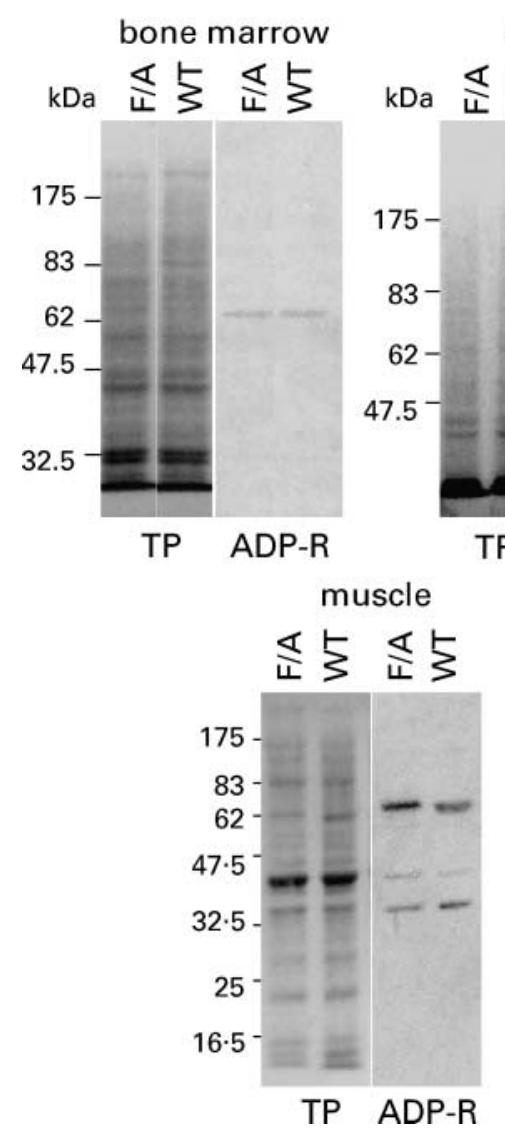

spleen
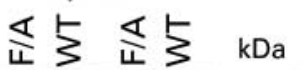

thymus

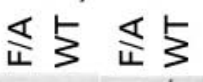

$75-$

$$
83
$$

$62-$

$47 \cdot 5-$

$32 \cdot 5-$

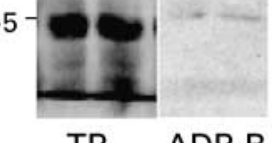

ADP-R

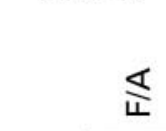

skin

TP ADP-R

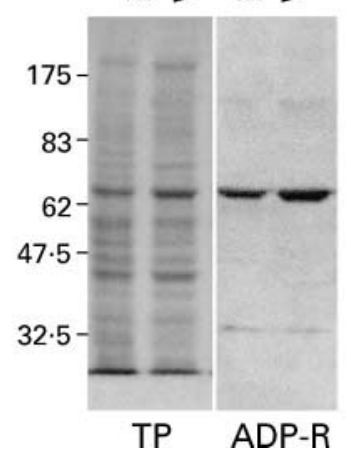

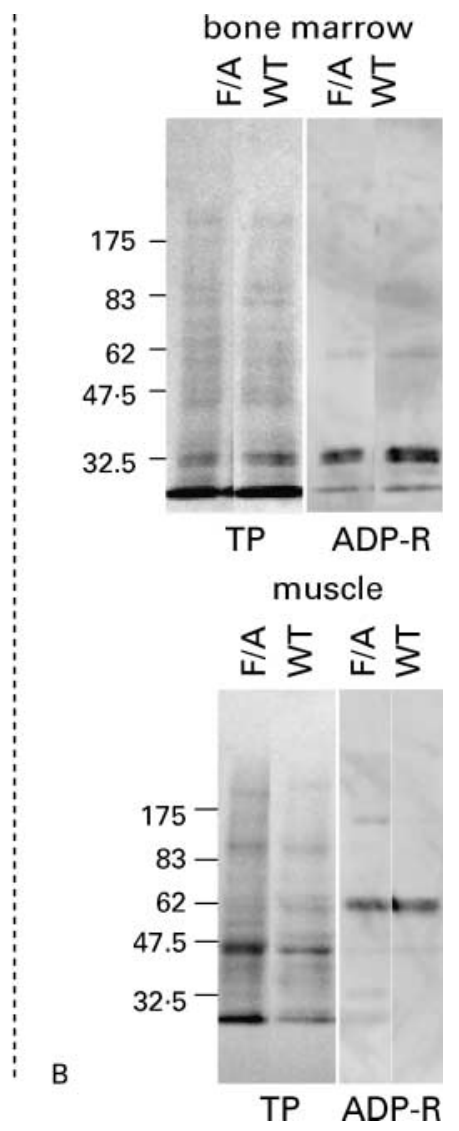

Fig. 2. Total and arginine ADP-ribosylated protein in organs of transgenic F/A-2 (F/A) and wild-type mice (WT). Total protein (TP) images are digital images of the blot using the top-illumination mode of the Lumi-Imager after amido black staining and methanol destaining. Arginine ADP-ribosylated (ADP-R) images were obtained by registering the chemiluminesence for 3 min with the Lumi-Imager. (A), Western blots stained with the rabbit anti-ADP-ribosylarginine antiserum (Schwab et al. 2000); (B), Western blot stained with rabbit ADP-ribosylguanidinobutyrate affinity-purified anti-ADP-ribose antiserum (Meyer \& Hilz, 1986). 
During the suckling period, circulating and tissue arginine concentrations in the most affected line (F/A-2) are approximately $30 \%$ of those present in wild-type animals (De Jonge et al. 1998, 2002a,b). In this study, protein-arginine ADP-ribosylation and protein-tyrosine nitration in the most affected organs of F/A-2 mice (haematopoietic organs, muscle and skin) were investigated.

\section{Protein-arginine ADP-ribosylation}

The anti-ADP-ribose antiserum detected several proteins. All protein bands were measured separately. In every organ tested, a protein of $65 \mathrm{kDa}$ was ADP-ribosylated. In addition, approximately 130,43 and $34 \mathrm{kDa}$ proteins bands were ADP-ribosylated in several tissues (Fig. 2(A)). With three out of four proteins being ADP-ribosylated to a lesser extent in F/A-2 mice than in wild-type controls, the effects of hypoargininaemia on ADP-ribosylation of proteins were most pronounced in skin. In this tissue, ADPribosylation of the $130 \mathrm{kDa}$ protein was reduced to $20 \%$ and that of the $65 \mathrm{kDa}$ protein to $50 \%$ in F/A-2 compared with wild-type mice. The degree of arginine ADP-ribosylation of the $43 \mathrm{kDa}$ ADP-ribosylated protein in skin and all ADP-ribosylated proteins in bone marrow, spleen, thymus and muscle protein did not, however, differ between F/A-2 and wild-type mice (Fig. 3). Another, often used, ADPribose antiserum (Hilz et al. 1986; Tanny et al. 1999) detected the same bands in bone marrow and muscle (Fig. 2(B)), although with a noticeable difference in the relative staining intensity of the bands, in particular the approximately $34 \mathrm{kDa}$ protein in bone marrow. This difference is most likely attributable to the fact that one

(A)

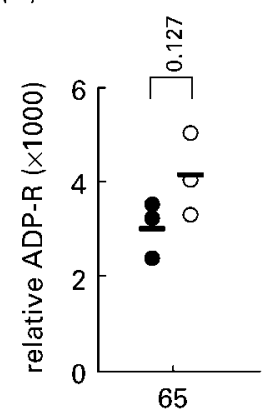

(D)

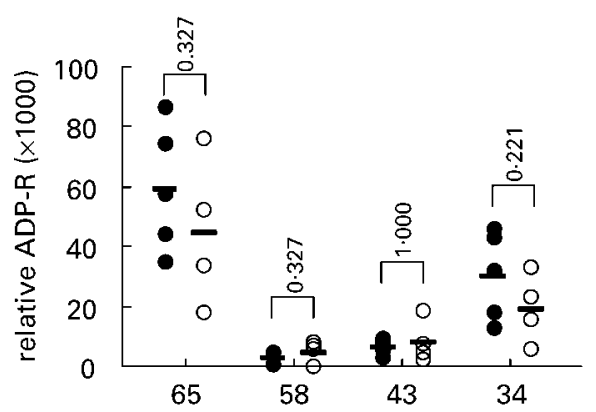

antiserum was raised against ADP-ribosyl-polyarginine (Schwab et al. 2000) and, hence, was probably specific for protein-arginine ADP-ribose, and the other was raised against ADP $\left[\mathrm{CH}_{2}\right]$-ribose coupled to bovine serum albumin (Meyer \& Hilz, 1986) and, hence, probably cross reacts with other ADP-ribosylated protein-amino acids (Hsia et al. 1985; Ziegler, 2000).

\section{Protein-tyrosine nitration}

The anti-nitrotyrosine antibody revealed a prominent nitrated approximately $250 \mathrm{kDa}$ protein in all tissues tested (Fig. 4). In bone marrow and muscle, proteins of 83, 64 and $40 \mathrm{kDa}$ were also visualised. Additional proteins of 175 and $98 \mathrm{kDa}$ were found in muscle and a protein of $31 \mathrm{kDa}$ was found in bone marrow. Protein nitration of the $83 \mathrm{kDa}$ protein in bone marrow and of the approximately $250 \mathrm{kDa}$ protein in spleen was higher in F/A-2 than in wildtype mice, whereas protein nitration of the $31 \mathrm{kDa}$ protein in bone marrow was lower in F/A-2 mice (Fig. 5). Except for the $31 \mathrm{kDa}$ protein in bone marrow, the average nitration of all detected proteins in bone marrow, spleen and thymus was higher in F/A-2 than in wild-type mice (Fig. 5).

\section{Discussion}

\section{Protein-arginine ADP-ribosylation}

Arginine deficiency in mice causes a reduction in growth of muscle, hair and B-cells, but the mechanism underlying this growth impairment is not known. To investigate whether the

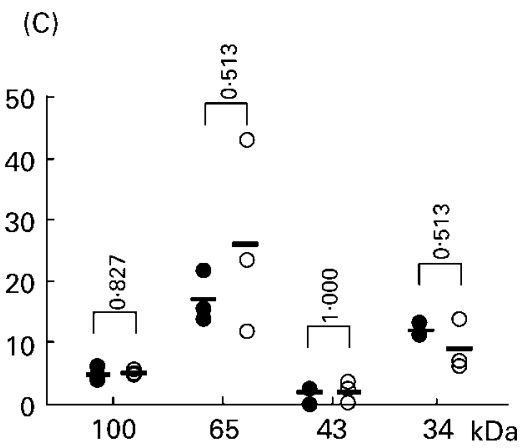

(E)

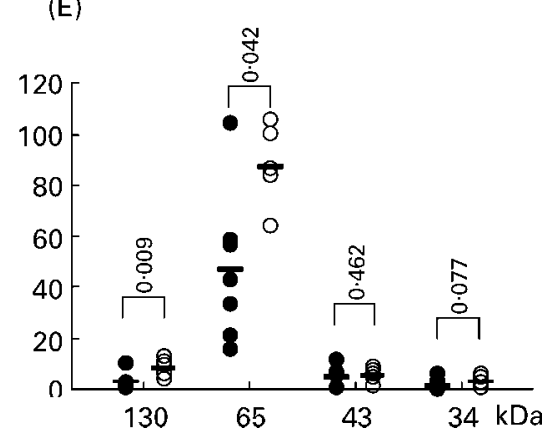

Fig. 3. ADP-ribosylation (ADP-R) of arginine residues in proteins from bone marrow (A), spleen (B), thymus (C), muscle (D) and skin (E) of transgenic F/A-2 (O) and wild-type () mice, using the rabbit anti-ADP-ribosylarginine antiserum. Relative ADP-R was calculated as the chemiluminescence of the specific band divided by the integrated density of the lane after the amido black staining. Scatter plots were used to show variation. $P$ values were calculated using the Mann-Whitney non-parametrical test. Horizontal bars represent the mean values. 

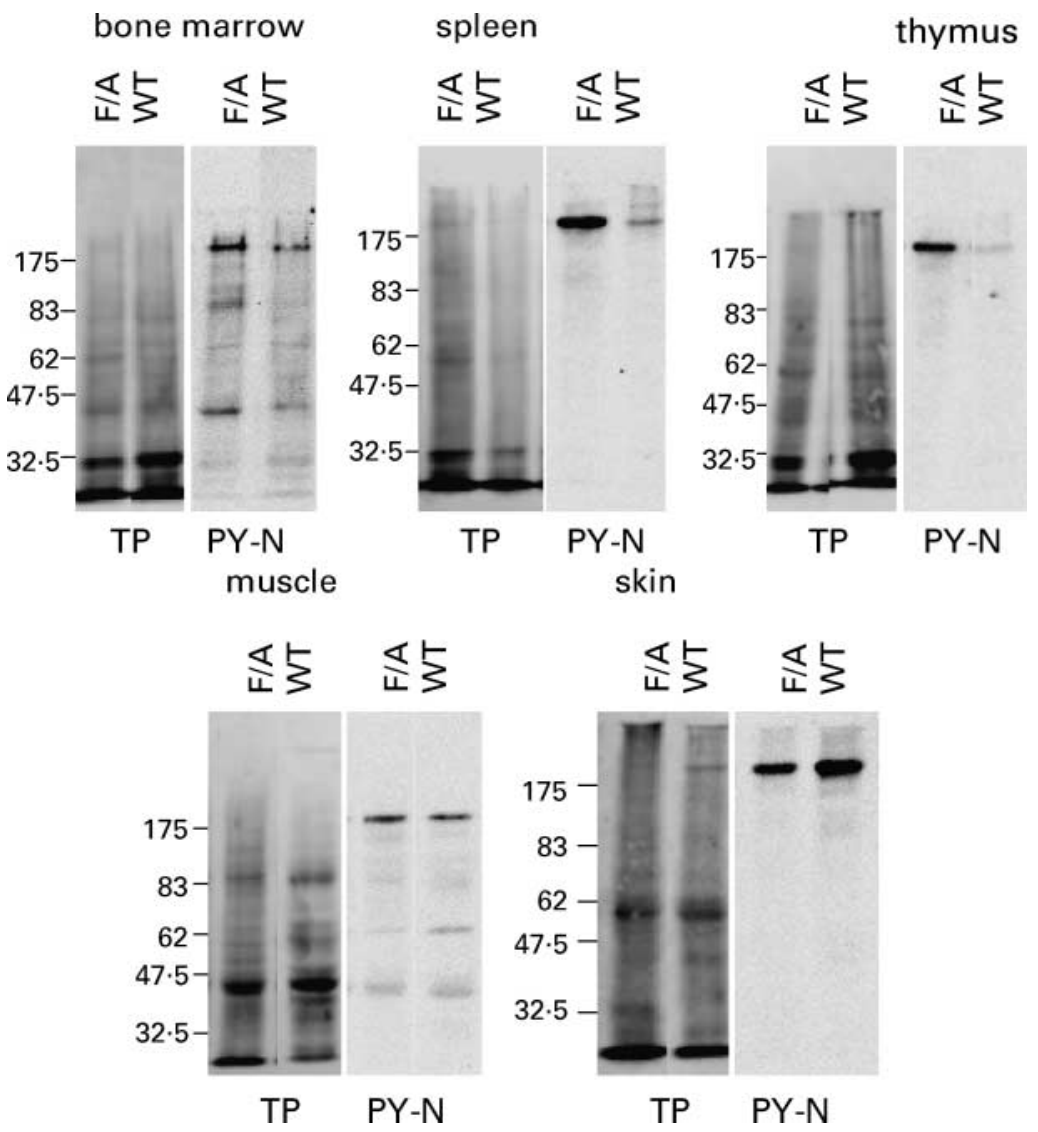

Fig. 4. Total and tyrosine-nitrated protein in organs of transgenic F/A-2 (F/A) and wild-type mice (WT). Total protein (TP) images are digital images of the blot using the top-illumination mode of the Lumi-Imager after amido black staining and methanol destaining. Protein-tyrosine nitrated images (PY-N) were obtained by registering the chemiluminesence for $3 \mathrm{~min}$ with the Lumi-Imager. Western blots were stained with a monoclonal antibody specifically detecting nitrotyrosine residues in proteins (ter Steege et al. 1998).

post-translational modifications of proteins by arginine ADP-ribosylation or tyrosine nitration might be involved, we compared arginine-deficient F/A-2 mice with wild-type mice. Protein-arginine ADP-ribosylation was assayed by Western blot using antisera that only recognise ADP-ribosylated arginine residues (Meyer \& Hilz, 1986; Schwab et al. 2000). To establish whether the degree of arginine ADP-ribosylation had changed as a result of chronic arginine deficiency, we related their signals to the amount of protein loaded in that lane as estimated from the integrated amido black signal. A limited number of proteins in each tissue were modified to a detectable extent. The similarity in the composition of this group of proteins in the respective organs investigated was striking, with the $65 \mathrm{kDa}$ protein being present in all tissues investigated, the $43 \mathrm{kDa}$ and $34 \mathrm{kDa}$ species in three out of five tissues and the $130 \mathrm{kDa}$ species in two out of five tissues. We did not differentiate between intracellular and plasma membrane proteins, but well-studied arginine ADP-ribosylated plasma-membrane proteins such as integrin $\alpha 7(97 \mathrm{kDa})$ in muscle (Zolkiewska \& Moss, 1993) and LFA-1 (dimer of 180 and $90 \mathrm{kDa}$ protein) in lymphatic tissue (Nemoto et al. 1996; Okamoto et al. 1998) were not detected. Also, arginine-rich histones (approximately $20 \mathrm{kDa}$ ), targets for intracellular ADP-ribosyltransferases (Kurokawa et al. 1995; Corda \& Di Girolamo, 2002, 2003), were not detected.
With the exception of skin, in which protein-arginine ADP-ribosylation changed in the opposite direction predicted by the hypothesis, the differences in protein-arginine ADP-ribosylation in arginine-deficient and control animals were minimal. The findings, therefore, contradict the hypothesis that there is competition between protein-bound and free arginine for mono-ADP-ribosylation, because arginine deficiency did not produce higher levels of protein-arginine ADP-ribosylation. Explanations for this finding could be that the activity of arginine-dependent ADP-ribosylating enzymes in suckling rodent is still low (Klebl et al. 1997; Adriouch et al. 2001) and that protein-bound arginine residues have a much lower $\mathrm{K}_{\mathrm{m}}$ for ADP-ribosyltransferase than free arginine. If the observed $\mathrm{K}_{\mathrm{m}}$ of agmatine, the ADP-ribose acceptor used in most ADP-ribosyltransferase assays (2-5 mM; Moss et al. 1997; Klebl et al. 1997), is any indication, this explanation seems realistic, because this value exceeds the circulating and tissue arginine concentration by approximately 50 -fold.

\section{Protein-tyrosine nitration}

As for protein-arginine ADP-ribosylation, the apparent similarity of the group of proteins in the respective tissues that shows detectable amounts of nitro-tyrosine is striking. In all tissues investigated, the $\sim 250 \mathrm{kDa}$ band represented the 

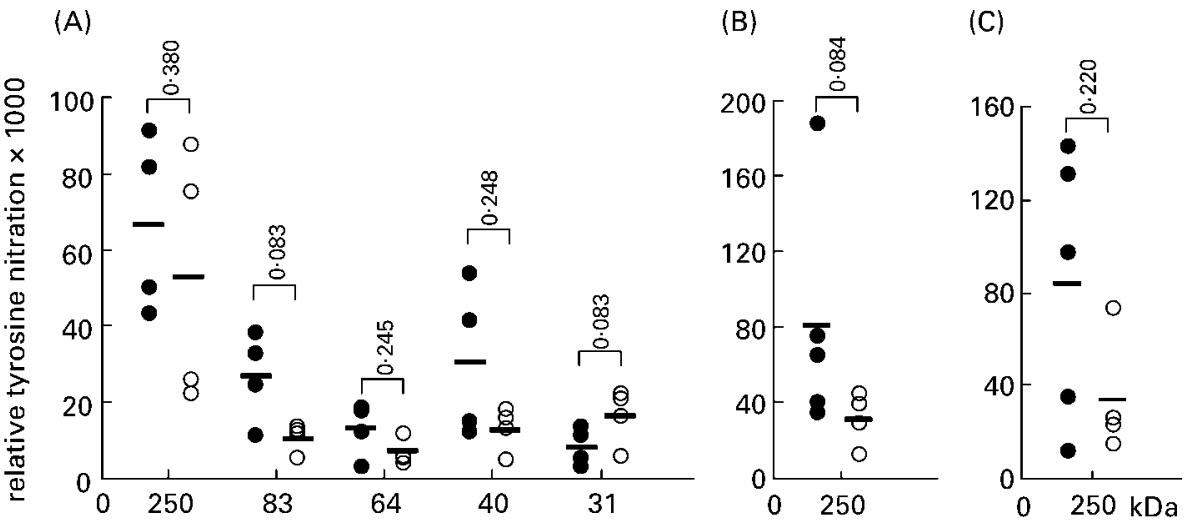

(D)

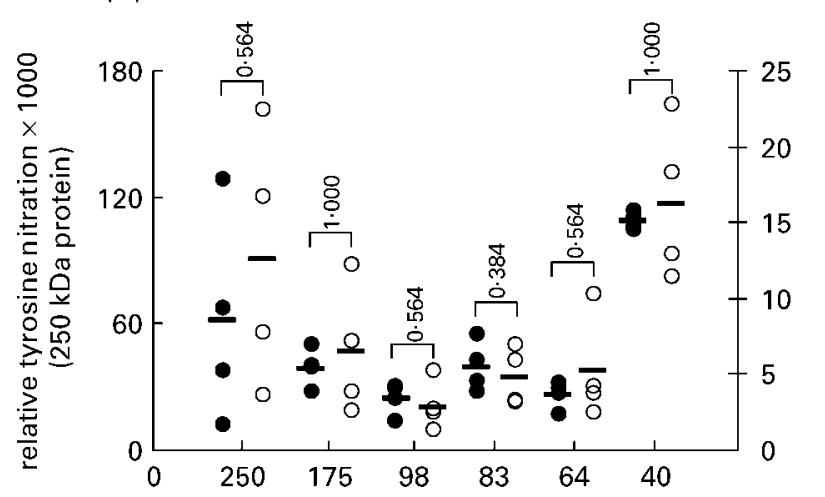

(E)

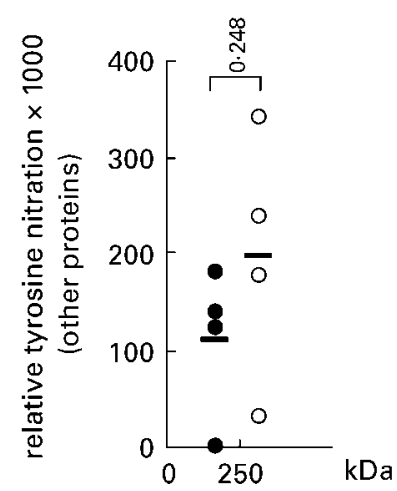

Fig. 5. Protein-tyrosine nitration in bone marrow (A), spleen (B), thymus (C), muscle (D) and skin (E) of transgenic F/A-2 (O) and wild-type () mice. Relative tyrosine nitration was calculated as the chemiluminescence of the specific band divided by the integrated density of the lane after amido black staining. Scatter plots were used to show variation. $P$ values were calculated using the Mann-Whitney non-parametrical test. Horizontal bars represent the mean values.

most prominent nitro-tyrosine-containing protein, while 83 , 64 and $40 \mathrm{kDa}$ bands were observed in bone marrow and muscle. Although the average degree of protein-tyrosine nitration in the immune organs (bone marrow, spleen and thymus) was $\sim 2$-fold higher in arginine-deficient compared with wild-type mice, the non-parametric test that we applied, to avoid assumptions on the distribution of the results, revealed that the difference approached significance $(P=0.08)$ for only three bands. Furthermore, the $31 \mathrm{kDa}$ band in bone marrow and several bands in muscle and skin showed an opposite tendency. Although plasma and tissue arginine levels in suckling F/A-2 mice were only $\sim 30 \%$ of that found in age-matched controls (De Jonge et al. 2002a), our findings suggest that these arginine levels $(\sim 60 \mu \mathrm{M})$ do not yet lead to the generation of substantial amounts of $\mathrm{O}_{2}^{-}$as a by-product of nitric oxide synthase-mediated NO production. Possibly, the absolute rather than the relative concentration of arginine should be considered, as $60 \mu \mathrm{M}$ still represents $\sim 50 \%$ of the adult arginine concentration. In agreement, we found that whole-body NO production, measured as citrulline production from arginine (Hallemeesch et al. 2003), is decreased from 238 (SEM 47) nmol/ $\mathrm{kg}$ body weight per min $(n 17)$ in adult control mice to 156 (SEM 26) $\mathrm{nmol} / \mathrm{kg}$ body weight per min $(n$ 13) in F/A-2 mice (YC Luiking, MM Hallemeesch, NEP Deutz and WH Lamers, unpublished results). With circulating and tissue arginine concentrations in adult F/A-2 mice amounting to $\sim 50 \%$ of that found in wild-type controls (De Jonge et al. 1998, 2002a,b), these numbers may also reveal a tendency, but again the difference was not significant $(P=0 \cdot 19$; twoway ANOVA).

\section{Conclusion}

Our findings appear to exclude protein-arginine ADP-ribosylation and protein-tyrosine nitration as arginine-dependent post-translational mediators of the arginine-deficiency phenotype in skin, muscle and immune system of suckling F/A-2 mice. Therefore, the mechanism underlying the F/A-2 phenotype remains unresolved. Assuming no as yet unknown arginine-dependent pathways, one or more of the metabolic or signal-transduction pathways shown in Fig. 1 should account for the observed phenotype. We previously showed that the tissue concentration of polyamines in F/A-2 mice is normal and that arginine, but not creatine, injections could rescue the phenotype (De Jonge et al. 2002a). A lack of charged arginyl-tRNA is an unlikely possibility, as the synthesis of the extremely arginine-rich protein trichohyalin in skin does not seem to be affected in F/A-2 mice compared with controls (De Jonge et al. 2002a). Most likely, therefore, signal-transduction via NO or agmatine is affected. 


\section{Acknowledgements}

The Dutch Foundation for Scientific Research (NWO) is acknowledged for grant number 902-23-098.

\section{References}

Adriouch S, Ohlrogge W, Haag F, Koch-Nolte F \& Seman M (2001) Rapid induction of naive T cell apoptosis by ecto-nicotinamide adenine dinucleotide: requirement for mono(ADPribosyl)transferase 2 and a downstream effector. J Immunol 167, 196-203.

Corda D \& Di Girolamo M (2002) Mono-ADP-ribosylation: a tool for modulating immune response and cell signaling. $S c i$ STKE 2002, E53.

Corda D \& Di Girolamo M (2003) Functional aspects of protein mono-ADP-ribosylation. EMBO J 22, 1953-1958.

Davis TA, Fiorott ML \& Reeds PJ (1993) Amino acid compositions of body and milk protein change during the suckling period in rats. $J$ Nutr 123, 947-956.

De Jonge WJ, Dingemanse MA, de Boer PA, Lamers WH \& Moorman AF (1998) Arginine-metabolizing enzymes in the developing rat small intestine. Pediatr Res 43, 442-451.

De Jonge WJ, Hallemeesch MM, Kwikkers KL, Ruijter JM, Gierde Vries C, van Roon MA, Meijer AJ, Marescau B, de Deyn PP, Deutz NE \& Lamers WH (2002a) Overexpression of arginase I in enterocytes of transgenic mice elicits a selective arginine deficiency and affects skin, muscle, and lymphoid development. Am J Clin Nutr 76, 128-140.

De Jonge WJ, Kwikkers KL, te Velde AA, van Deventer SJ, Nolte MA, Mebius RE, Ruijter JM, Lamers MC \& Lamers WH (2002b) Arginine deficiency affects early B cell maturation and lymphoid organ development in transgenic mice. J Clin Invest 110, 1539-1548.

Greenacre SA \& Ischiropoulos H (2001) Tyrosine nitration: localisation, quantification, consequences for protein function and signal transduction. Free Radic Res 34, 541-581.

Hallemeesch MM, Dejonge CHC, De Jonge WJ, Soeters PB, Lamers WH \& Deutz NE (2003) Chronic reduction of circulating arginine by ornithine transcarbamylase deficiency causes a reduction of cNOS-mediated NO production. Am J Physiol $\mathbf{2 8 5}$, E871-E875.

Herzfeld A \& Raper SM (1976) Enzymes of ornithine metabolism in adult and developing rat intestine. Biochim Biophys Acta 428, 600-610.

Hilz H, Fanick W \& Klapproth K (1986) 2'-Phosphoadenylylation of eukaryotic proteins: a type of covalent modification. Proc Natl Acad Sci USA 83, 6267-6271.

Hsia JA, Tsai SC, Adamik R, Yost DA, Hewlett EL \& Moss J (1985) Amino acid-specific ADP-ribosylation. Sensitivity to hydroxylamine of [cysteine(ADP-ribose)]protein and [arginine(ADP-ribose)]protein linkages. $J$ Biol Chem 260, 16187-16191.

Hurwitz R \& Kretchmer N (1986) Development of argininesynthesizing enzymes in mouse intestine. Am J Physiol 251, G103-G110.

Klebl BM, Gopel SO \& Pette D (1997) Specificity and target proteins of arginine-specific mono-ADP-ribosylation in T-tubules of rabbit skeletal muscle. Arch Biochem Biophys 347, $155-162$.

Klotz LO, Schroeder P \& Sies H (2002) Peroxynitrite signaling: receptor tyrosine kinases and activation of stress-responsive pathways. Free Radic Biol Med 33, 737-743.

Kurokawa T, Fujimura Y, Takahashi K, Chono E \& Ishibashi S (1995) Reduction of mono(ADP-ribosyl)ation of histones in rat testis by gonadotropin-testosterone system. Biochem Biophys Res Commun 215, 808-813.

McDonald LJ \& Moss J (1994) Enzymatic and nonenzymatic ADP-ribosylation of cysteine. Mol Cell Biochem 138, 221-226.

Meyer T \& Hilz H (1986) Production of anti-(ADP-ribose) antibodies with the aid of a dinucleotide-pyrophosphatase-resistant hapten and their application for the detection of mono(ADPribosyl)ated polypeptides. Eur J Biochem 155, 157-165.

Minetti M, Mallozzi C \& Di Stasi AM (2002) Peroxynitrite activates kinases of the src family and upregulates tyrosine phosphorylation signaling. Free Radic Biol Med 33, 744-754.

Moss J, Stevens LA, Cavanaugh E, Okazaki IJ, Bortell R, Kanaitsuka T, Mordes JP, Greiner DL \& Rossini AA (1997) Characterization of mouse Rt6.1 NAD:arginine ADPribosyltransferase. J Biol Chem 272, 4342-4346.

Nagy LE \& Kretchmer N (1988) Utilization of glutamine in the developing rat jejunum. J Nutr 118, 189-193.

Nemoto E, Yu Y \& Dennert G (1996) Cell surface ADP-ribosyltransferase regulates lymphocyte function-associated molecule1 (LFA-1) function in T cells. $J$ Immunol 157, 3341-3349.

Okamoto S, Azhipa O, Yu Y, Russo E \& Dennert G (1998) Expression of ADP-ribosyltransferase on normal T lymphocytes and effects of nicotinamide adenine dinucleotide on their function. J Immunol 160, 4190-4198.

Okazaki IJ \& Moss J (1999) Characterization of glycosylphosphatidylinositol-anchored, secreted, and intracellular vertebrate mono-ADP-ribosyltransferases. Annu Rev Nutr 19, 485-509.

Riby JE, Hurwitz RE \& Kretchmer N (1990) Development of ornithine metabolism in the mouse intestine. Pediatr Res $\mathbf{2 8}$, $261-265$.

Schwab CJ, Colville MJ, Fullerton AT \& McMahon KK (2000) Evidence of endogenous mono-ADP-ribosylation of cardiac proteins via anti-ADP-ribosylarginine immunoreactivity. Proc Soc Exp Biol Med 223, 389-396.

Tanny JC, Dowd GJ, Huang J, Hilz H \& Moazed D (1999) An enzymatic activity in the yeast Sir2 protein that is essential for gene silencing. Cell 99, 735-745.

ter Steege JC, Koster-Kamphuis L, van Straaten EA, Forget PP \& Buurman WA (1998) Nitrotyrosine in plasma of celiac disease patients as detected by a new sandwich ELISA. Free Radic Biol Med 25, 953-963.

Tsuchiya M \& Shimoyama M (1994) Target protein for eucaryotic arginine-specific ADP-ribosyltransferase. Mol Cell Biochem 138, $113-118$.

Visek WJ (1984) An update of concepts of essential amino acids. Annu Rev Nutr 4, 137-155.

Wu G (1997) Synthesis of citrulline and arginine from proline in enterocytes of postnatal pigs. Am $J$ Physiol 272, G1382-G1390.

Wu G \& Knabe DA (1995) Arginine synthesis in enterocytes of neonatal pigs. Am J Physiol 269, R621-R629.

Xia Y, Dawson VL, Dawson TM, Snyder SH \& Zweier JL (1996) Nitric oxide synthase generates superoxide and nitric oxide in arginine-depleted cells leading to peroxynitrite-mediated cellular injury. Proc Natl Acad Sci USA 93, 6770-6774.

Xia Y \& Zweier JL (1997) Superoxide and peroxynitrite generation from inducible nitric oxide synthase in macrophages. Proc Natl Acad Sci USA 94, 6954-6958.

Ziegler M (2000) New functions of a long-known molecule. Emerging roles of NAD in cellular signaling. Eur J Biochem 267, 1550-1564.

Zolkiewska A \& Moss J (1993) Integrin alpha 7 as substrate for a glycosylphosphatidylinositol-anchored ADP-ribosyltransferase on the surface of skeletal muscle cells. J Biol Chem 268, $25273-25276$ 